\title{
The Subjective Journalist: Exploring Bias in Marketing Communication Using Language Cues: An Abstract
}

\author{
Christopher Lee and Bradley Fay
}

\begin{abstract}
In an increasingly digital age many sports organizations, such as Major League Baseball (MLB), have hired in-house reporters to cover games. For example, MLB.com employs a reporter for every team who covers the team, writes game recaps, etc. As an example, a game between the Los Angeles Dodgers and Chicago Cubs features a writeup from the perspective of the home team reporter and away team reporter. The MLB.com arrangement presents a unique opportunity to explore biases given the reporters are observing the same event but from a different perspective (win versus loss). In addition, given both reporters are hired by Major League Baseball's media arm and the writeups are featured on MLB.com, the editorial guidelines are expected to be the same. Subtle bias in these articles may impact fans emotions towards a game or team and, ultimately, affecting their long term loyalty to an organization. Although BIRGing (Cialdini et al. 1976), brought attention to pronoun usage by fans, are writers inadvertently communicating subtle biases in their articles? Can analyzing articles by team reports show how language choice is influenced by winning or losing?

This research is important as these game recaps are often the most quickly published articles on a game for a fan to read and attract readers via an inbound marketing approach (Halligan and Shah 2014). The articles are posted on the official team website giving fans an opportunity to read and share through social media. As such, and a potential avenue for future research, subtle language cues driven by situational factors (i.e., winning and losing) in these articles may impact consumers emotions and attitudes towards an organization. This research shows subtle, but important, biases in marketing communication. Computational analysis of marketing messages presents a new approach to better understand how situational factors (i.e., winning and losing) and psychological processes lead to a particular word choice.
\end{abstract}

References Available Upon Request

C. Lee $(\bowtie) \bullet$ B. Fay

Temple University, Philadelphia, PA, USA

e-mail: chrislee@temple.edu; bradley.fay@asu.edu

(C) Academy of Marketing Science 2017

P. Rossi (ed.), Marketing at the Confluence between Entertainment and Analytics, Developments in Marketing Science: Proceedings of the Academy of Marketing Science, DOI 10.1007/978-3-319-47331-4_233 